\title{
Dilemas éticos y jurídicos a propósito del aborto en Chile
}

\author{
Adriana Palavecino Cáceres \\ Licenciada en Ciencias Jurídicas y Sociales U. de Chile \\ Magister en Derecho con mención en Derecho Privado U. de Chile \\ Docente Escuela de Derecho U. de Talca. \\ Email: apalavecino@utalca.cl
}

\begin{abstract}
Resumen: El drama de dos niñas de 13 y 11 años que han quedado embarazadas tras ser violadas por sus padres ha reinstalado con fuerza en Chile el debate sobre el aborto. Al respecto puede observarse que la discusión se ha desenvuelto en dos planos. Desde una perspectiva subjetiva, se cuestiona la moralidad de la decisión de interrumpir un embarazo. Desde una perspectiva objetiva, cuál es la legislación y política pública más adecuada para regular el aborto inducido. En este trabajo se abordan las principales cuestiones que surgen en una y otra dimensión. Así, nos preguntamos: ¿Desde cuándo existe el nasciturus?; ¿Cuál es el status moral y jurídico del mismo?; ¿Existe un derecho al aborto?; ¿Despenalización del aborto?; ¿En qué circunstancias?; ¿Qué voluntades se requiere para recurrir a él? Concluimos con una propuesta bioética sobre cómo encarar el asunto en nuestro país.
\end{abstract}

Palabras clave: aborto, nasciturus, bioética, moral.

\section{Ethical and legal dilemmas in regards to abortion in Chile}

\begin{abstract}
The drama of two girls aged 13 and 11 years old pregnant after being raped by their fathers has reinstalled intensely the discussion about abortion in Chile. In this respect we can see that the discussion has developed in two spheres. From a subjective point of view, on the morality of the decision to terminate a pregnancy. From an objective perspective, on what is the best law and public policy to regulate induced abortion. This paper addresses the major issues that arise in both dimensions. Thus, we ask: Since when exists the 'nasciturus'? What is his the moral and legal status? Is there a right to abortion? Depenalization of abortion? Under what circumstances? Who should authorize the abortion decision? We end with a bioethical proposal on how to address the issue in our country.
\end{abstract}

Key words: abortion, nasciturus, bioethics, morality.

\section{Dilemas éticos e jurídicos a propósito do aborto no Chile}

Resumo: O drama de duas meninas com idades entre 13 e 11 anos que ficaram grávidas depois de ser estuprada por seus pais tem reinstalado com força no Chile o debate sobre o aborto. A este respeito, pode-se notar que a discussão tem sido desdobrada em dois planos. Do ponto de vista subjetivo, a moralidade da decisão de interromper a gravidez é questionada. Do ponto de vista objetivo, planteiase quais são a legislação e as políticas públicas mais adequadas para regular o aborto provocado. Precisamente, neste trabalho se abordam as principais questões que se colocam numa ou outra dimensão. Então, perguntamos: Desde quando existe o 
feto?; Qual é o status moral e jurídico do mesmo?; Existe um direito ao aborto?; A descriminalização do aborto?; Em que circunstâncias?; Que vontade é necessária para usá-lo? Concluímos com uma proposta bioética sobre a forma de abordar estas questões em nosso país.

Palavras-chave: aborto, nasciturus, bioética, moral.

$* * *$

\section{Aborto terapéutico y no terapéutico}

El diccionario de la Real Academia Española define aborto como la interrupción del embarazo por causas naturales o deliberadamente. En cuanto al significado etimológico, en latín aborto se compone de las palabras $a b$ (separación, privación) y ortus (nacimiento), entendiéndose, entonces, como la privación del nacimiento.

En 1963, la Corte Suprema dictaminó que era la interrupción maliciosa del embarazo con el propósito de evitar el nacimiento del feto o detener el curso natural del embarazo.

Se distingue entre aborto terapéutico y no terapéutico. En Chile se permitió el aborto terapéutico a través del Código Sanitario entre los años 1931 y 1989. Durante este período, toda mujer cuya vida estuviera en peligro podía solicitar un aborto si contaba con la aprobación de dos médicos. Sin embargo, el artículo único de la Ley N¹8.826 (D.O. 15/09/1989) reemplazó el artículo 119 del Código Sanitario indicando que: "No podrá ejecutarse ninguna acción cuyo fin sea provocar un aborto”. En los años previos al Código Sanitario, el aborto inducido permaneció en el ámbito de la vida privada y no constituía preocupación de la opinión pública, de las autoridades ni de otras instituciones ${ }^{1}$.

Siguiendo a Figueroa ${ }^{2}$, se ha definido tradicionalmente el aborto terapéutico como aquél en que la vida de la madre está en peligro debido a la continuación del embarazo, es decir, existe una disyuntiva entre la vida de la madre y la del feto, sobre todo en hipótesis de embarazo extrauterino. De dos males se escoge el mal menor que es la muerte del feto.

No obstante, hoy en día, la expresión “aborto terapéutico” se ha extendido a cualquier fetopatía aunque ni la vida de la madre ni la del embrión estén en peligro de muerte, por lo tanto, el límite entre el aborto terapéutico y el no terapéutico se hace difuso. A la base de este planteamiento está la idea de que no se trata solamente de traer niños al mundo sino de que éstos puedan relacionarse adecuadamente en el futuro con un mundo y una familia concretos, lo que no ocurriría en casos de cualquier anomalía profunda como un grave deterioro cerebral de la criatura. En este sentido, Ribes se pregunta: “¿La presencia de un hijo profundamente débil no engendrará graves trastornos en el hogar polarizando toda solicitud de la madre en detrimento de los demás hijos y del marido o creando dificulta- 
des materiales o relacionales cada vez mayores que lleguen a ser insoportables? (Citado por Figueroa 2007:.317)”3.

Reconocemos validez a este planteamiento, pues evidentemente, se refiere a graves enfermedades que someten a todo el grupo familiar a situaciones de permanente tensión y zozobra, como sucede por ejemplo con el síndrome de Lesch-Nylan, la anencefalia o la adrenoleucodistrofia. Desde una perspectiva ética cabe preguntarse si no es un acto de tortura obligar a la madre a gestar y, luego, criar a un hijo en estas circunstancias. Personalmente, un sentimiento humanitario me inclina a estar más de acuerdo con un aborto temprano si la madre así lo decide.

En contra de esta posición se ha dicho que aceptar el aborto en estos casos podría operar como un freno a la investigación y a los avances en la medicina para buscar tratamiento y hasta cura a los trastornos graves del feto. No me parece un argumento suficiente. La carga de dar a luz y luego cuidar un hijo en tan insufrible situación, solo puede ser fruto de la libre decisión de la mujer, no es humanitario ni justo imponerle la conducta de mártir. De otra parte, los niños serán tratados como un medio para descubrir tratamientos y cura a estas enfermedades, una suerte de conejillos de India, degradando su dignidad humana y, eventualmente, dando lugar a situaciones de encarnizamiento médico.

Para Ugarte el llamado aborto terapéutico ${ }^{4}$ no puede ser nunca lícito porque el embrión no puede ser conceptualmente considerado como injusto agresor. Tampoco las personas pueden disponer de la vida humana y el buen fin no justifica los medios malos. Por otro lado, en el estado actual de la medicina son casos difíciles o raros aquéllos en que solo sacrificando al hijo podría salvarse a la madre. Es evidente que se refiere al concepto tradicional de aborto terapéutico que vimos recién.

Según este autor, el argumento de la injusta agresión no podría jamás aplicarse porque, por principio, la presencia del feto en las entrañas maternas se debe a la actividad de la madre y es cumplimiento de una ley natural propia y no ajena a la agredida. Volveré sobre este punto más adelante.

Asimismo, los detractores del aborto plantean que detrás de la posición que extiende el concepto de aborto terapéutico a cualquier fetopatía, se ocultan oscuras intenciones eugenésicas que se manifiestan en una tendencia a la inducción del aborto en casos de malformaciones congénitas, como labio leporino y paladar hendido.

Cabe indicar que, dentro de esta posición conservadora se acepta, sin embargo, la hipótesis del aborto indirecto, que se justificaría éticamente por el principio del doble efecto, a saber, cuando se aplique a la madre un tratamiento, remedio, o terapia, indispensables para salvar la vida amenazada si la muerte del embrión o feto es solo un efecto colateral o accidental no buscado ni como fin ni como medio. Es decir, cuando el aborto es un efecto 
accidental o colateral, pero para que se dé es necesario que lo que ponga en peligro la vida de la madre no sea el embarazo sino un mal o enfermedad de su cuerpo, y que el tratamiento o remedio esté determinado a combatir ese mal o enfermedad. Ejemplos de ello serían la radioterapia para combatir el cáncer y la extirpación de la trompa de Falopio en el caso de embarazo ectópico con hemorragia.

En cuanto al aborto no terapéutico, se ha definido como el consentido en que no existe la disyuntiva de salvar la vida de la madre o la del hijo, esto es, aquél que -de no mediar las manipulaciones abortivas- las posibilidades de vida se inclinan tanto a favor de la madre como del hijo ${ }^{5}$. Revisaré a continuación algunos de los clásicos debates éticos en torno a este tipo de aborto.

\section{Dilemas éticos en torno al aborto no terapéutico}

\section{¿Desde cuándo existe el nasciturus?}

Para saber desde cuándo estamos en presencia de “el que está por nacer”, existen al menos cinco posturas que son las siguientes:

- Con la fertilización del óvulo por el espermio;

- Con la anidación del embrión (día 14º);

- Con la actividad cerebral del embrión;

- Con la viabilidad del feto;

- Con la relacionalidad o culturización del feto.

\section{Con la fertilización del óvulo por el espermio}

De acuerdo a esta postura, existe un individuo de la especie humana desde la fertilización del óvulo por el espermio. Los autores que la defienden tienen una marcada adhesión al Catecismo de la Iglesia Católica, al punto de citar entre sus argumentos la Encíclica Evangelium Vitae del Papa Juan Pablo II. Según este documento, con la fecundación comienza una nueva vida que jamás llegaría a ser una persona humana si entonces no lo es. La genética confirma esta evidencia: desde el primer momento está programado lo que será este viviente. Y se preguntan ¿Cómo un individuo humano podría no ser una persona humana? ${ }^{6}$.

Según los partidarios de esta posición, en el cigoto está todo lo que es determinante para el desarrollo cualitativo y cuantitativo que experimenta ese embrión unicelular desde el estado de tal hasta el de individuo adulto con órganos definitivos perfectamente constituidos. Lo que permitiría afirmar que es el que es y no otro, es decir, su propia identidad.

Por otro lado, si el embrión no es ser humano desde el estado de 
cigoto, tendría que haber en él un cambio de naturaleza biológica debido a una causa exterior que lo transformase de no humano en humano, añadiéndole algo a tal efecto. Pero no hay dato alguno que permita suponer la existencia de tal causa. Cuando los 23 cromosomas paternos se encuentran con los 23 cromosomas maternos está reunida toda la información genética necesaria y suficiente para determinar cada una de las cualidades innatas del nuevo individuo. Que el niño deba luego desarrollarse durante nueve meses en el vientre de la madre no cambia estos hechos. La fecundación extracorpórea demuestra que el ser humano comienza con la fecundación.

Las principales objeciones a esta posición son: $1^{\circ} \mathrm{El}$ ser humano comienza propiamente con la implantación del embrión en el útero y $2^{\circ}$ No hay individuo porque antes del décimo cuarto día pueden darse gemelos monocigóticos o quimeras.

Respecto a la primera objeción, los partidarios de esta posición rebaten que ni el contacto físico con el útero ni la conexión sanguínea con la madre podrían explicar la transformación de un simple tejido humano en un individuo humano. La implantación no produce un salto cualitativo para que se constituya el respectivo ser humano. La coexistencia del embrión con la madre comienza mucho antes de la implantación.

Respecto a la segunda objeción, Singer plantea irónicamente que "Si consideramos al embrión un individuo desde la concepción -llamémosle Marion-, entonces ¿Qué le sucede a Marion si el embrión se divide? ¿Los gemelos recién formados son Marion y un nuevo gemelo, por ejemplo, Ruth? ¿ $\mathrm{O}$ se trata de nuevos gemelos, por ejemplo Ruth y Ester? Ambas respuestas suscitan paradojas. Si Marion todavía existe ¿Cuál de los dos gemelos es? No hay una base para decir que uno de ellos está más estrechamente vinculado a la Marion original que el otro. Pero si ninguno de los gemelos es Marion ¿Qué le ha sucedido? ¿Se ha desvanecido? ¿Deberíamos lamentar la pérdida de un individuo humano como yo lamentaría la pérdida de una de mis hijas, aún cuando fuera reemplazada por otras dos? (Singer 1997: 101)"”.

Los partidarios de esta posición argumentan en contra que, la generación de gemelos monocigóticos es algo excepcional. El cigoto en el 99 a 99,6\% de los casos da origen a un solo individuo, lo que permite concluir que está en sí determinado a ello. Por otro lado, no se trata de la generación de dos embriones a partir de un sistema matriz carente de individualidad en cuanto organismo humano sino de un primer embrión, que no deja por ello de seguir su propio e individual desarrollo, que origina un segundo en un momento dado. Esto se confirmaría con el hecho de que existen gemelos monocigóticos con genomas distintos en que uno ha presentado síndrome de Down y el otro no, lo que indicaría que uno comienza después del otro. 


\section{Con la anidación del embrión (día 14²)}

Quienes defienden esta tesis indican que, producida la implantación, las células del blastocisto han alcanzado un nivel de diferenciación y especialización que les hace perder su carácter totipotente. Queda establecida la individualización en sentido biológico. Un número creciente de legislaciones reconocen en el día $14^{\circ}$ posterior a la fecundación una barrera a la disponibilidad de la vida humana en su fase embrionaria: España, Reino Unido, Alemania y Suecia.

Las principales objeciones que se plantean a esta posición son: $1^{\circ} \mathrm{El}$ embrión es un ser humano en potencia y por lo tanto debemos respetar su vida; $2^{\circ}$ El ser humano no debe disponer de organismos vivos de su propia especie para satisfacer objetivos que estime valiosos. $3^{\circ}$ ¿Por qué el día $14^{\circ}$ y no el día $13^{\circ}$ ó el $15^{\circ}$ ?

La primera objeción resulta pueril, pues bajo la óptica de la vida humana potencial toda célula de nuestro cuerpo también es un ser humano en potencia, un eventual clon que deberíamos preservar.

Respecto a la segunda objeción, Soto $^{8}$ argumenta que, no se ve razón por la que la vida humana considerada como un valor, deba escapar a la suerte que es común a todos los demás valores morales: la relatividad. Todo valor, incluida la vida humana, posee un peso relativo en el sentido de que siempre estará sujeto a la ponderación con otros valores concurrentes. Y no parece descabellado suponer que pueda ceder frente a otros valores, los que puestos en la situación concreta, podamos reconocerles mayor peso. El hecho que en las circunstancias del caso se confiera primacía a un cierto valor sobre otro, no implica admitir que el valor que se hace prevalecer posea una primacía permanente sobre el valor que en ese caso se sacrifica.

Por último, la objeción respecto de la arbitrariedad de designar el día $14^{\circ}$, según este autor, es una crítica que puede plantearse tanto a esta posición como a las demás pues dependerá del hecho al cual se asigne la determinación de la existencia del nasciturus. Y no se trata de algo que resuelva la biología pues los hechos, en este caso, biológicos, por sí solos no permiten colegir deberes. Es una toma de posición avizorando el horizonte de valoraciones más generales y compartidas en nuestra sociedad.

\section{Con la actividad cerebral del embrión}

Para los partidarios de esta posición, la actividad cerebral es el indicador aceptado en todo el mundo civilizado, por eso una vez desaparecida la actividad cerebral de una persona, los cirujanos se dejan caer sobre el cadáver con su corazón aún latiendo para beneficiarse de sus órganos sanos por medio de un trasplante. El embrión en sus primeras etapas no tiene actividad cerebral, ni siquiera posee cerebro, luego es posible soste- 
ner que todavía no es un ser humano, no es una sustancia individual de naturaleza racional, siguiendo a Boecio en su definición clásica de persona.

Singer plantea que si hacemos la comparación con un feto de menos de tres meses un pez mostraría más señales de conciencia. Sugiere que acordemos no dar más valor a la vida del feto que a la de un animal no humano dado un nivel similar de racionalidad, conciencia de sí mismo, conocimiento, capacidad de sentir, etc. Este autor se plantea a favor de una Ética Universal o Global no discriminatoria.

El dolor y el sufrimiento son malos y deberían ser evitados o minimizados, independientemente de la raza, el sexo o la especie del ser que sufra. Indica que antes de las dieciocho semanas de gestación no existe ninguna base para creer que el feto necesite ser protegido de una investigación que le perjudique. Después de ese período sí necesita que se le proteja de posibles daños. Con la misma base que lo necesitan los animales no humanos que sienten pero que no son conscientes de sí mismos ${ }^{9}$.

\section{Con la viabilidad del feto}

Para esta posición el criterio determinante es la posibilidad de supervivencia de manera autónoma del feto respecto de su madre, lo que nos permitiría afirmar que efectivamente estamos en presencia del que está por nacer, es decir, del que está próximo a nacer. Este fue el criterio adoptado en una famosa decisión judicial por la Suprema Corte de Estados Unidos, en el caso Roe vs. Wade (1973), conforme con el cual el feto adquiere status moral y protección legal cuando llega al punto en el que puede sobrevivir fuera del útero materno.

La principal objeción que se plantea a esta postura es que depende del avance de la medicina por lo que este criterio resulta más arbitrario y discrecional que los anteriores.

\section{Con la relacionalidad o culturización del feto}

Según los que adhieren a esta postura, el embrión de nuestra especie se hace propiamente humano al culturizarse, y ello ocurre cuando el embarazo es deseado y la madre reconoce plenamente a su hijo como una entidad ajena a ella misma, verificándose una relación interpersonal entre dos sujetos distintos.

Corrientes contemporáneas han destacado la "apertura" como dimensión clave de la persona humana, en el sentido de "trascendencia” o relación con otras personas, apertura al otro. Hay autores que han puesto de relieve la comunicación intersubjetiva. Otros han indicado como elementos característicos de la persona la vivencia de los valores, el compromiso 
con su sociedad y la solidaridad con las demás personas. La persona no es algo hecho, cerrado de una vez para siempre, sino un quehacer continuo, una tarea abierta en el tiempo y en la historia. Para la antropología contemporánea la persona es una unidad estructural abierta al mundo y a los otros. Es un sujeto frente a otros sujetos o frente a objetos.

Si bien puede objetarse el altísimo grado de discrecionalidad de este criterio y desecharlo sin más, a la base del mismo está la interrogante de ¿Cuándo nos volvemos propiamente humanos? O la de ¿Qué nos hace propiamente humanos y nos distingue de otras especies animales?

En relación a este primer dilema ético, por mi parte, concuerdo plenamente con el profesor Soto en orden a que cualquier criterio para determinar desde cuándo existe el nasciturus puede ser tachado de arbitrario, pues dependerá, por una parte, de la disciplina desde la cual analicemos la cuestión, como la Filosofía, la Antropología, la Biología o el Derecho, como también, de las propias convicciones valóricas que tengamos.

Entonces, en mi opinión, las opciones son dos: o nos enfrascamos en una suerte de torre de Babel, en que cada cual transmite en una frecuencia distinta; o intentamos hacer un esfuerzo "transdisciplinario" siguiendo a Lolas ${ }^{10}$, que implique compartir un contenido, un cometido y un contexto, para buscar un criterio que goce de legitimación social. Evidentemente, este criterio deberá ser plasmado en la ley, que es la “declaración de la voluntad soberana”, pues es con las armas del Derecho con las que se debe resolver la cuestión. Creo que el criterio que podría constituir un punto de equilibrio entre las posturas más extremas y tendría mayor sustento en la moral social de nuestro país sería el de la implantación a partir del día $14^{\circ}$ siguiente al de la concepción, lo que haría lícita la distribución de la píldora del día después en todos los casos.

\section{¿Cuál es el status moral y jurídico del nasciturus?}

Este es otro dilema no menos complejo de resolver que el anterior. En nuestra doctrina podemos distinguir tres posiciones:

- El nasciturus es persona

- Se rechaza la identidad entre nasciturus y persona

- El nasciturus no es persona pero es sujeto de derechos.

\section{El nasciturus es persona} nales.

Esta es la postura mayoritaria en la doctrina y jurisprudencia nacio-

Quienes adhieren a esta posición no siguen la noción de persona del 
Código Civil. Fundamentalmente, sostienen que, los seres humanos son sujetos de protección constitucional; el preembrión y un ser humano nacido gozan de la misma protección desde un punto de vista constitucional; y el aborto debe entenderse prohibido siempre.

$\mathrm{Al}$ respecto, Soto Kloss indica: “....aun cuando no expresa la Constitución -como decíamos- una noción de persona, sin embargo se encarga muy precisamente de reconocer que quien está por nacer es una persona; en otros términos, la criatura que está en el vientre materno es una persona”. En el mismo sentido, Cea declara que: “...el ser humano en el seno materno es, desde su concepción, sujeto de derechos fundamentales y que deben serle respetados, comenzando por la vida (Citados por Figueroa 2007: 98)" ${ }^{11}$.

En cuanto a la jurisprudencia a favor de esta tesis, podemos citar el fallo del recurso de protección Rol Nº 850 de 28/05/2001 contra la píldora del día después. La Corte de Apelaciones de Santiago lo rechazó por falta de legitimación activa. Pero en un voto disidente, la Ministra Morales declara que el cigoto es potencialmente persona desde su concepción. Asimismo, el fallo de la Corte Suprema en apelación de la sentencia anterior, causa Rol N 2186 de 2001, declara que el ser humano tiene derecho a la vida en los siguientes términos: "Se hace evidente que el que está por nacer, cualquiera sea la etapa de su desarrollo prenatal -pues la norma constitucional no distingue- tiene derecho a la vida...”. Como también el fallo del Tribunal Constitucional de 18/04/2008, sobre la píldora del día después, el cual indica en su considerando quincuagésimo séptimo: "Junto con asegurar el derecho a la vida y a la integridad física y psíquica de la persona, nuestra Carta Fundamental ordenó "La ley protege la vida del que está por nacer”. La intención del Constituyente fue confiar al legislador las modalidades concretas de protección de la vida del que está por nacer, en el entendido que se trata de un ser existente e inserto en la concepción de persona, en cuanto sujeto de derecho, a que alude el encabezado del artículo 19. Este mandato al legislador importa la protección de un derecho y no sólo el bien jurídico de la vida, distinción que no es menor para estos sentenciadores. En efecto, si sólo se hubiese protegido la vida, en cuanto bien jurídico, bastaría que el legislador hubiese consagrado mecanismos que aseguraran al nasciturus la viabilidad de la vida intrauterina hasta el nacimiento".

La principal crítica que se hace a esta posición es su marcada fundamentación religiosa lo que suscita dificultades en un estado laico, democrático, inclusivo y tolerante. Esta postura religiosa parece contradictoria pues se supone que le asigna igual valor a la vida prenatal y a la nacida, pero en verdad no es así: la vida prenatal no se puede eliminar nunca pero la vida nacida sí. El caso más obvio es el de la pena de muerte que sigue siendo aceptada por el Catecismo de la Iglesia Católica.

También se objeta que esta postura no concuerde con la valoración que subyace en el ordenamiento jurídico chileno. Diversas normas revelan 
que existe una valoración distinta de la vida del nasciturus y la del ya nacido. Esto explica que el Código Civil exija el nacimiento para conferir existencia legal, que la Constitución dé un tratamiento distinto al que está por nacer en el artículo $19 \mathrm{~N}^{\circ} 1$ inciso $2^{\circ}$, y que el Código Penal establezca para el aborto una pena inferior al infanticidio y al parricidio y regule el aborto en una sección distinta a la de los delitos contra las personas. Si la valoración fuera la misma, la diferencia de trato que la ley da al homicidio y al aborto sería inconstitucional.

Por otro lado, que la Constitución separe el reconocimiento del derecho a la vida de todas las personas de la protección que ordena brindar al que está por nacer revela, indudablemente, un tratamiento diverso del nasciturus. El único sentido lógico de ese enunciado es que establece un deber de protección para la vida del no nacido. Si se lo entendiera como confiriendo un derecho a la vida para el no nacido, esa norma sería redundante con el inciso primero.

Finalmente, se le critica que entienda el mandato constitucional de protección de la vida del nasciturus como una prohibición absoluta, porque proteger es un verbo distinto de prohibir y no toda prohibición ha de ser necesariamente absoluta. Es posible proteger hasta un cierto grado y permitir el aborto también hasta un cierto grado, cuya determinación precisa corresponderá a la ley. Además debe tenerse en cuenta que si el derecho a la vida de las personas nacidas no es absoluto, puesto que la propia Constitución admite la pena de muerte, menos puede serlo la vida de quien no es persona ni titular de derechos. En consecuencia, el inciso segundo del numeral $1^{\circ}$ del artículo 19 no puede interpretarse como que confiere protección absoluta a la vida del que está por nacer.

Concuerdo con estas objeciones pues tanto la Constitución, el Código Civil como el Código Penal contienen una valoración distinta de la vida, en ningún caso idéntica o superior, del que está por nacer respecto de los ya nacidos.

\section{Se rechaza la identidad entre nasciturus y persona}

Bascuñán sostiene que el nasciturus carece de titularidad del derecho a la vida pero esto no significa que no deba ser protegido ${ }^{12}$. Solo son personas los nacidos, desde una perspectiva constitucional.

Por otro lado, los derechos fundamentales, según quienes sostienen esta posición, presentan una doble dimensión: como un conjunto de valores objetivos positivizados -bienes jurídicos fundamentales- y como auténticos derechos subjetivos que garantizan directamente las situaciones y actuaciones individuales. Por consiguiente, el derecho fundamental a la vida contiene al mismo tiempo el reconocimiento de un derecho subjetivo a la vida a quien tenga capacidad de ser titular del mismo -la persona, esto es, los nacidos- y la identificación de un bien jurídico protegido constitucio- 
nalmente -la vida humana en toda su evolución y desarrollo. En cuanto al nasciturus solo presentaría el segundo elemento. Romeo ${ }^{13}$ y la mayoría de la doctrina española comparte esta idea. Por su parte, el Tribunal Constitucional Español ha declarado que: “...la vida del nasciturus, en cuanto éste encarna un valor fundamental -la vida humana- garantizado en el artículo 15 de la Constitución, constituye un bien jurídico cuya protección encuentra en dicho precepto fundamento constitucional” ${ }^{14}$.

\section{El nasciturus no es persona pero es sujeto de derechos}

Esta posición intermedia implica no negar al embrión un estatuto personal pero sin conferirle la misma dignidad que se reconoce a las personas.

Figueroa sostiene que el nasciturus no es persona en el sentido técnico del Código Civil pero es sujeto de derecho y, como tal, titular del derecho a la vida. El embrión humano antes de la implantación es cosa, luego de ésta es sujeto de derecho, pero no de todos. Sin embargo, el embrión preimplantatorio no debe ser tratado como "cualquier" cosa, pues se trata de un ser humano en potencia respecto del cual no es posible actuar sin límites ${ }^{15}$. En cuanto al embrión implantado, no puede entendérsele objeto de un derecho de propiedad, es un sujeto de diversos derechos, unos puros y simples y otros sujetos a modalidades. Figueroa señala que el embrión implantado como titular de derechos es en verdad una persona aunque el ordenamiento jurídico chileno le niegue tal atributo.

\section{¿Existe un derecho al aborto?}

Este es otro aspecto interesante de analizar desde una perspectiva ética. El pensamiento feminista ha proclamado el derecho al aborto que asistiría a la mujer para poder disponer libremente de su vida y su destino. Las feministas difieren de los planteamientos liberales, evaluando el aborto en un marco más amplio, considerando el papel que juega la regulación legal en perpetuar la opresión de las mujeres. Según esta perspectiva, dada la subordinación femenina, los argumentos que intentan justificar el derecho a abortar en la autonomía de las mujeres o en la falta de personalidad del feto son inapropiados. Más bien el derecho a abortar se funda en la idea de que es moralmente incorrecto exigir que grupos oprimidos se sacrifiquen, cuando tales sacrificios tienden a agravar su situación de subordinación. Esta propuesta basada en la igualdad estima que el aborto debe ser despenalizado porque su punibilidad fortalece la opresión sexual ${ }^{16}$.

De otra parte, el aborto desde esta perspectiva feminista debe ser contextualizado en situaciones concretas, sociales y personales, que pongan énfasis en los intereses de las mujeres. En este sentido, Dworkin plantea que: "Las leyes que prohíben el aborto o dificultan o encarecen su 
obtención privan a las mujeres embarazadas de una libertad y oportunidad que para muchas de ellas resulta crucial. Una mujer que, al no poder acceder a un aborto temprano y seguro, es forzada a dar a luz un niño que no desea, no goza ya del dominio sobre su propio cuerpo, la ley la somete a una suerte de esclavitud. Sin embargo, éste es tan sólo el comienzo. Para muchas mujeres, dar a luz niños no deseados significa la destrucción de sus propias vidas, o porque ellas mismas son todavía niñas, o porque ya no les será posible trabajar o estudiar más, o vivir de una manera que les resulte significativa, porque no pueden mantener a sus hijos (por supuesto, estos diferentes tipos de perjuicios se multiplican e intensifican si el embarazo tiene su origen en una violación o incesto o si el niño nace con serios impedimentos físicos o psíquicos). La adopción, incluso cuando es posible, no elimina estos perjuicios, pues muchas mujeres sufrirían un grave dolor emocional durante muchos años si entregaran a su hijo a otras personas para que los criaran y amaran” ${ }^{17}$.

El caso Roe versus Wade en 1973 marcó un hito en Estados Unidos en materia de derecho al aborto, pues la Corte Suprema declaró al respecto que: “... una mujer embarazada tiene un derecho constitucional a la privacidad en materia de procreación y que este derecho general incluye el derecho al aborto si ella y el médico deciden a favor del mismo”. Añadió que las razones que pueda tener un Estado para anular este derecho criminalizando el aborto no constituían razones imperativas durante los dos primeros trimestres del embarazo y concluyó que un Estado no podía prohibir el aborto durante ese período.

Sin embargo, el planteamiento feminista critica esta noción de privacidad por ser demasiado abstracta y reforzar la distinción entre lo público y lo privado. Mackinnon señala que: "es precisamente en la esfera de lo privado donde se dan la mayoría de los abusos y agresiones a las mujeres y donde se encuentran en una posición subordinada (...) Cuando se hace una separación tajante entre lo público y lo privado, y se afirma que el aborto es una cuestión privada, se impide el examen moral de un contexto que es fuente importante de injusticias e inequidades de género (Citada por Luna-Salles 2008:263)" ${ }^{18}$

Otros autores fundan el derecho al aborto en la autonomía de las mujeres. Así, Bascuñán sostiene que el principio de autonomía puede ser contrarrestado por un bien preponderante que a sus expensas se trate de proteger: por ejemplo, podría hacerse una transfusión de sangre contra la voluntad del dador, en forma excepcional cuando fuera el único medio de salvar la vida de otra persona, y no acarrease a aquél mayores complicaciones. No se podría, en cambio, forzar a una persona a permanecer nueve meses conectada a un sistema de diálisis sanguínea de otra, ni aunque éste fuera el único medio de salvar la vida de esa otra, y siendo indiscutible el derecho a la vida de este último, porque ello iría claramente más allá del límite de las afectaciones permisibles del cuerpo de una persona y de su autonomía, en beneficio ajeno. Ni la misma madre tendría la obligación de salvar de esa manera la vida del hijo ya nacido. 
Para este autor, la cuestión es si la mujer tiene o no el deber de tolerancia del embarazo y de ser garante de su progresión hasta el parto, fundado en la condición natural de vida del embrión o feto. Si se resuelve por la afirmativa, se reconoce al embrión o feto no un status igual al del ya nacido, sino superior, desde que a favor del hijo ya nacido no se podría exigir a la madre semejante afectación de su cuerpo y sacrificio de su autonomía. La pregunta es, entonces ¿Qué razones tenemos para asignar esa carga a la mujer respecto de ese embrión o feto?

Ugarte objeta esta posición indicando que en esa etapa de desarrollo del hijo, el organismo de la madre está natural e intrínsecamente destinado también a él, en condición de instrumento, parte de su propio cuerpo. Agrega que: "La humanidad ha de propagarse y la mujer tiene naturalmente el deber de albergar en sus entrañas al hijo en gestación, y de formarlo y mantenerlo, con la contribución biológica propia de la madre gestante (Ugarte 2006: 328)" ${ }^{19}$.

El planteamiento de Ugarte es sorprendente, pues niega la autonomía de la mujer transformándola en un mero instrumento para la propagación de la especie humana, carente de dignidad y libertad ${ }^{20}$. Me pregunto cómo puede sostenerse este argumento ante la tragedia de una niña de $13 \mathrm{u}$ 11 años que queda embarazada producto de una violación. Es inaceptable que se niegue a las mujeres la soberanía sobre su propia vida y sus cuerpos $\mathrm{y}$, en cambio, se conviertan en meras incubadoras, una suerte de esclavas de la procreación. La maternidad así planteada, es retrógrada y anuladora.

\section{¿Despenalización del aborto?}

La posición en contra cita la Encíclica Evangelium Vitae del P. Juan Pablo II, la cual en su $\mathrm{N}^{\circ} 58$ plantea que: "Quien se elimina es un ser humano que comienza a vivir, es decir, lo más inocente en absoluto que se pueda imaginar: ijamás podrá ser considerado un agresor, y menos aún un agresor injusto! Es débil, inerme, hasta el punto de estar privado incluso de aquella mínima forma de defensa que constituye la fuerza implorante de los gemidos y del llanto del recién nacido. Se halla totalmente confiado a la protección y al cuidado de la mujer que lo lleva en su seno. Sin embargo, a veces, es precisamente ella, la madre, quien decide y pide su eliminación, e incluso la procura (Ugarte 2006: 321)” ${ }^{21}$.

En definitiva, la cuestión se reduciría a determinar si el embrión o feto es un agresor injusto. En la negativa, no estaría permitido el aborto. Sin embargo, sabido es que existen otras hipótesis en que, no obstante tratarse de agresores inocentes es lícito eliminarlos para preservar otros bienes que se considerar más valiosos, como el caso de un avión secuestrado por terroristas que pretende dejarse caer sobre un poblado, donde es indudable que los pasajeros de ese avión son agresores inocentes, y aún así, resultaría justificable destruir la aeronave antes de que pueda poner en peligro la vida de los habitantes del lugar. 
Respecto a la posición a favor de la despenalización del aborto, la atribución a la vida humana de un valor intrínseco o "sagrado” es un juicio religioso, según Dworkin, porque es esencialmente una afirmación de carácter religioso la de que la importancia de la vida humana trasciende la experiencia subjetiva, beneficiándose de alguna fuente de valor metafísica, que está más allá de dicha experiencia. La atribución de un valor intrínseco a la vida es un juicio religioso incluso cuando la hace un ateo pues sus convicciones sobre la vida humana pueden coincidir con los de un devoto católico, un judío, un musulmán. El Estado no puede coartar la libertad de las mujeres en orden a la procreación -autonomía procreativa- para preservar un valor intrínseco cuando éste es de carácter religioso. Insiste en que, la defensa del valor intrínseco de la vida humana no puede autorizar al Estado para coartar la libertad cuando el efecto sobre un grupo de ciudadanos sea muy grave. Aquí la coacción se ejercería sobre las mujeres embarazadas lo que es muy grave porque criminalizar el aborto puede destruir la vida de una mujer.

Ugarte replica que no se trata de defender un valor sagrado pues prescindiendo de esta consideración, el aborto sería igualmente ilícito porque iría en contra del deber de perpetuar la especie. Afirma que, la autonomía procreativa de la mujer no existe, pues la mujer tendría más bien un deber procreativo. Actuada ya la vida sexual y producido el embarazo, el cuerpo de la madre se subordina al del embrión.

Nuevamente sorprende la forma en que intenta Ugarte sortear la crítica de Dworkin de que el valor sagrado de la vida humana tiene sustento metafísico y no jurídico. ¿Deber de perpetuar la especie? ¿Dónde está consagrado jurídicamente? Lo único que se nos viene a la mente es el mandato bíblico de "Procread y multiplicaos...”, contenido en Génesis 1, 28, pero nada parecido existe en nuestro ordenamiento jurídico.

\section{¿En qué circunstancias debiera ser lícito el aborto?}

Bajo qué supuestos se podría legalizar el aborto es otra cuestión interesante de dilucidar. Figueroa es partidario de la despenalización del aborto, pero no en la sociedad actual, sino en una donde existiera una amplia educación sexual y el acceso generalizado a métodos anticonceptivos; un conjunto de medidas de protección y estímulo tales como subsidios maternales especialmente altos; asignaciones familiares adecuadas, preferencias en cuanto a posibilidades laborales, discriminaciones positivas y, en general, otras medidas para que las mujeres no miren el futuro nacimiento de su hijo como una desgracia ${ }^{22}$.

Por su parte, Soto $^{23}$ plantea que podría configurarse la causal de exención de la responsabilidad penal de inexigibilidad de otra conducta, que supone que la persona a la que se pretende imputar la comisión de un delito no ha de haber tenido la razonable posibilidad de actuar de un modo diverso a como lo hizo. En este sentido, no resulta justificado que el Estado 
dirija el máximo reproche contra una persona que, dadas las circunstancias objetivas en que obró no pudo razonablemente actuar de un modo diverso. Siguiendo a este autor, nadie podría exigirle razonablemente a una persona normal puesta en las mismas circunstancias que una mujer con riesgo de muerte, una mujer violada, una mujer cuyo hijo viene con graves anomalías, o una mujer pobre que apenas subsiste con los hijos que tiene, en condiciones de total hacinamiento y miseria, que se abstenga de abortar si esa fuera su decisión. Subyace la idea de que la norma no puede pretender imponer una conducta de mártir a una mujer en tales circunstancias.

Agrega que, la falta prácticamente absoluta de una educación sexual, el acceso virtualmente nulo a la anticoncepción, la existencia de un poder judicial que rasga vestiduras en nombre de la vida humana para oponerse a las formas más elementales de anticoncepción, los altos niveles de pobreza, etc. todo ello redunda en un fortalecimiento de los argumentos para despenalizarlo. Según este autor, en un mundo ideal y benefactor como el que propone el profesor Figueroa, tendríamos razones más frívolas para justificar el aborto que las que tenemos hoy. Personalmente creo que el sentido del planteamiento de Figueroa es que en tal escenario la despenalización del aborto no se traduciría en un aumento indiscriminado de éste, sino en una opción entre muchas.

\section{¿Qué voluntad sería necesaria para recurrir al aborto, si este fuera lícito?}

Algunos autores plantean que debe concurrir la voluntad de ambos progenitores, sin embargo, la ley francesa de 1982 requiere tan solo la voluntad de la mujer si ésta es mayor de $\operatorname{edad}^{24}$. Somos de la opinión que quien debe decidir preponderantemente sobre el aborto es la mujer afectada, pues es ella quien soportará, más que nadie, las consecuencias de tal decisión. Por lo demás, en nuestra sociedad, si una mujer decide practicarse un aborto no es precisamente porque tiene al padre de la criatura a su lado apoyándola.

En Inglaterra se conoce el caso Kelly vs. Kelly, en que el marido de una mujer que estaba embarazada presentó un recurso que tenía por objeto evitar que ésta abortara. El marido recurrió en representación del nasciturus. La Corte lo interpretó como que el nasciturus tenía un derecho a permanecer en el vientre de la madre. Se resolvió que en esa legislación no existe tal derecho.

Resulta interesante responder a esta interrogante cuando la embarazada es menor de edad o incapaz como ha sucedido en los mediáticos casos que inspiraron este artículo ${ }^{25}$. En Estados Unidos se planteó el caso Gillick, en que se autorizó el aborto contra la opinión de los padres y se consintió en que la menor se implantase un dispositivo intrauterino. En este caso, la menor presentaba además un trastorno mental leve. 
Barcia ${ }^{26}$ explica que, en los países del Common Law para solucionar este conflicto se aplica el principio del interés superior del niño, de acuerdo a las siguientes condiciones:

- Que la menor entienda los consejos y riesgos del aborto.

- Que no sea posible persuadir a la menor de informar a sus padres, y el médico ponga todo el esfuerzo en convencerla de hacerlo.

- Que la menor consienta en el aborto.

- El aborto debe ser legal.

Entonces, es preciso determinar la madurez de la menor para decidir por sí misma y si su deseo de abortar está en consonancia con su interés superior. El fundamento constitucional estaría en el derecho de los menores a la privacidad. En Estados Unidos se reconoce a los menores, al igual que a los adultos, un derecho a la privacidad el que se expresa en la decisión de abortar. La Corte ha indicado que constitucionalmente no puede darse a los padres un veto generalizado. En algunos estados los mayores de cierta edad -15 años- pueden decidir libremente si abortar o no. Pero respecto de los menores de esa edad se aplican los criterios de madurez e interés del menor.

Si el aborto se legalizara en Chile, habría que preguntarse si, como en los casos tan trágicos de las niñas de 13 y 11 años embarazadas producto de violaciones, sería necesaria la sola voluntad de las menores y/o la de sus padres y, en subsidio, la del tribunal.

$\mathrm{Al}$ respecto, Barcia se refiere a la regulación en nuestro ordenamiento jurídico del principio del ejercicio progresivo de los derechos del niño. Dicho principio implica determinar en qué áreas y con qué extensión se estimará a los niños y adolescentes como plenamente capaces para tomar decisiones sobre su propia vida y concluye que a partir del artículo 16 inciso $3^{\circ}$ de la Ley de Tribunales de Familia, será desde los 14 años, pues a partir de esa edad el precepto los considera adolescentes, no ya niños, sin perjuicio de que antes de esa edad deban ser escuchados respecto de las decisiones que les afecten. Y éste sería el precepto rector en cuanto al ejercicio de los derechos de la personalidad del adolescente, no los de índole patrimonial respecto de los cuales seguiría rigiendo el Código $\mathrm{Civil}^{27}$.

\section{Reflexiones finales}

1) La revisión del estado actual de la cuestión, esto es, el debate ético-jurídico en torno al aborto inducido en nuestro país, puede que resulte un tanto extenuante. La polarización de las posturas y los múltiples conflictos de derecho que el tema suscita, no permiten avizorar que el problema del aborto se resuelva de manera satisfactoria en el corto plazo, si la discusión se mantiene en la estratósfera como una lucha de poder entre posturas ideológicas antagónicas que defienden sus métodos e interpretaciones, sin escucharse entre sí, ni menos a las afectadas. 
2) Sin embargo, urge promover un amplio debate social sobre la realidad del aborto en nuestro país con el propósito de buscar criterios para determinar medidas legislativas y de política pública eficaces, que den respuesta concreta a situaciones tan dramáticas como las de las niñas de 13 y 11 años que resultaron embarazadas producto de una violación.

3) Indudablemente, se debe revisar la actual legislación altamente restrictiva y discriminatoria en materia de derechos sexuales y reproductivos de las mujeres, porque vulnera la Convención sobre Eliminación de Todas las Formas de Discriminación contra la Mujer, tratado internacional ratificado por Chile en 1989, y porque lo único que ha logrado es impedir que las mujeres adopten decisiones fundamentales sobre su cuerpo y su propia vida.

4) Estimamos que todo intento de reforma legislativa debe ser antecedido por un proceso de reflexión y debate que persiga dar legitimación social a las decisiones. Imagino este debate bioético como una instancia lo más inclusiva posible que incorpore no solo a quienes deben tomar decisiones sobre la materia -autoridades y expertos- sino también a aquéllos que se verán afectados por tales decisiones. El debate debe trasladarse y comprometer a todos los actores sociales, porque -como dice Habermas- en una sociedad democrática una articulación de las necesidades, según criterios del saber técnico, tan solo puede quedar ratificada "en la conciencia de los actores políticos mismos (Habermas 1999: 150)" ${ }^{28}$. Los expertos no pueden sustituir en este acto de ratificación a aquéllos que tienen que salir fiadores con su vida entera de las nuevas interpretaciones de las necesidades sociales y de los medios que se acepten para la solución de las situaciones problemáticas.

5) Asimismo, este debate bioético debe darse en un clima dialógico en que los interlocutores no tengan por único propósito hacer prevalecer su punto de vista, sino por el contrario, se logre una convención semántica, en el sentido que plantea Lolas "en que las voces sin ser iguales, valgan igual (Lolas 2002: 40)” ${ }^{29}$. Solo después de producido este debate bioético en los términos planteados, es el legislador quien ha de hacerse cargo de resolver en torno al aborto, para evitar que las soluciones sigan entregadas a la subjetividad paternalista de los médicos o de los jueces. ¿Y por qué el legislador? Porque más que los médicos y los jueces, detenta un título de legitimidad democrática, constituyéndose en el representante de las personas afectadas.

6) Pero no se trata de que el legislador lo resuelva del mismo modo paternalista que el médico o el juez, en definitiva, no debe resolverlo "por" las afectadas sino que reconocer a ellas en este ámbito específico, la autodeterminación que el ordenamiento jurídico garantiza de manera general a los individuos. No se puede pasar por alto en este punto que la Constitución Política reconoce la autonomía decisoria como valor o principio base de la institucionalidad (art. $1^{\circ}$ inc. $1^{\circ} \mathrm{CPR}$ ). En efecto, cuando el art. $1^{\circ}$ declara que: "Las personas nacen libres..." no hace un enunciado pura- 
mente eufónico ni una constatación histórica o sociológica, sino que establece un standard de conducta según el cual toda persona debe ser tratada como agente moral responsable de sus propias decisiones y, por ende, como titular de un espacio de decisión y de actuación en que no caben en principio intromisiones externas. El precepto constitucional está aludiendo a la autonomía decisoria, vale decir, a la libertad según la concibe Kant como autolegislación: emplazarse a sí mismo bajo la ley del sí mismo.

7) Por consiguiente, el Estado no puede oponerse al ejercicio de decisiones que puede adoptar la persona sobre su propio cuerpo pues es el ámbito psicofísico, el núcleo primario sobre el cual cada sujeto debería estar en condiciones de poder disponer libremente. Hay que considerar como un dato decisivo que el reconocimiento de la autonomía significa concebir a la persona como agente moral responsable de sus propias decisiones y que "cuanto más fundamental sea y mayor alcance tenga una determinada decisión sobre la vida de un individuo, más sustancial es el interés de éste por disfrutar de autodeterminación para tomarla (Buchanan-Allen-otros 2002: 202)" ${ }^{30}$. 


\section{Notas}

${ }^{1}$ Dides 2006: 219-229.

${ }^{2}$ Figueroa 2007: 213.

${ }^{3}$ Citado por Figueroa 2007:317.

${ }^{4}$ Este autor indica que la expresión de aborto terapéutico es contrahecha desde que salvar una vida suprimiendo otra no es terapia alguna. Ugarte 2006: 328.

${ }^{5}$ Figueroa 2007: 214.

${ }^{6}$ Ugarte 2006: 320.

${ }^{7}$ Singer 1997: 101.

${ }^{8}$ Soto 2002: 75 .

${ }^{9}$ En http://www.lcc.uma.es/ ppgg/libros/psinger.html, consultada el 15 de junio de 2013.

${ }^{10}$ Lolas 2002: 38.

${ }^{11}$ Citados por Figueroa 2007: 98.

12 Bascuñán 2004: 49.

${ }^{13}$ Romeo 1994: 70.

${ }^{14}$ Barcia 2000: 13.

${ }^{15}$ Figueroa 2007:150.

${ }^{16}$ Luna-Salles 2008: 260.

${ }^{17}$ Citado por Ugarte 2006: 314.

${ }^{18}$ Citada por Luna-Salles 2008:263.

${ }^{19}$ Ugarte 2006: 328 .

${ }^{20}$ Es similar al argumento por el cual algunos justificaban la pervivencia del estatuto de hijos ilegítimos. Su mantención era necesaria para promover la institución del matrimonio. Los hijos ilegítimos, desprotegidos legalmente, eran usados como un medio para promover esta institución.

${ }^{21}$ Ugarte 2006: 321.

${ }^{22}$ Figueroa 2007: 219. 
${ }^{23}$ Soto 2001:521.

${ }^{24}$ Figueroa 2007: 218.

${ }^{25}$ Según el estudio titulado "Madres-niñas adolescentes de 14 años y menos. Un grave problema de salud pública no resuelto en Chile", de la Universidad de Chile, dos tercios de los escolares dicen no recibir educación sexual en sus colegios. Las embarazadas de 11 a 14 años representan poco menos del 3 por ciento de la población de madres. Las embarazadas de este grupo eran 1.058 al año 2003. Y la tendencia es al alza desde 1993.Los niños que son hijos de adolescentes no son esperados y eso provoca que nazcan en un entorno que no los quiere, por lo que la tasa de maltrato, accidentes en el hogar y abandono es mucho mayor en este grupo. Según Ramiro Molina, médico e investigador del Centro de Medicina Reproductiva de la Universidad de Chile (Cemera): “Una jovencita de Cerrillos tiene 35 veces más posibilidades de ser madre antes de los 14 que una que reside en Vitacura. ¿Qué pasa ahí, es que las niñas de Vitacura no tienen relaciones sexuales tan tempranamente? Puede ser, pero también puede que tengan mayor acceso a anticonceptivos, más educación y no podemos descartar que también tengan mejor acceso a la interrupción clandestina profesionalizada del embarazo”. Molina-Molina-González 2007: 79.

${ }^{26}$ Barcia 2000: 22.

${ }^{27}$ Barcia 2011: 384. Este planteamiento guarda armonía con lo dispuesto en el artículo 6 del D.S. $N^{\circ} 49$ de 2012 del Ministerio de Salud que contiene el Reglamento para el ejercicio del derecho a recibir educación, información y orientación en materia de regulación de la fertilidad, cuando dispone que: "En el caso que se trate de un método anticonceptivo de emergencia, que sea solicitado por una persona menor de 14 años, el facultativo o funcionario que corresponda, tanto en el sector público o privado, procederá a la entrega de dicho medicamento, debiendo informar de este hecho con posterioridad, a su padre, madre o adulto responsable que la menor señale, para lo cual consignará los datos que sean precisos para dar cumplimiento a esta obligación”. Es decir, la información a los padres solo se precisaría en el caso de niñas menores de 14 .

${ }^{28}$ Habermas 1999: 150.

${ }^{29}$ Lolas 2002: 40.

${ }^{30}$ Buchanan-Allen-otros 2002: 202. 


\section{Bibliografía}

Barcia, R. (2000), "Derecho a la vida del nasciturus en España”, Ius et Praxis, año 6, $\mathrm{N}^{\circ} 2$, Talca.

Idem (2011), Fundamentos del Derecho de Familia y de la Infancia, Editorial Thomsons Reuters Puntolex, Santiago de Chile.

Buchanan, A. y otros (2002), Genética y Justicia, Cambrigde University Press, Madrid.

Dides, C. (2006), “Aportes al debate sobre el aborto en Chile: Derechos, Género y Bioética”. Acta bioeth., año 2006, vol.12, no.2, pág. 219-229.

Figueroa, G. (2007), Derecho Civil de la Persona, del Genoma al nacimiento, Editorial Jurídica de Chile, Santiago de Chile.

Figueroa, R. (2007), “Concepto de Persona, titularidad y derecho a la vida”, Revista de Derecho, V. 20, N², Valdivia.

Habermas, J. (1999), "Política cientifizada y opinión pública" (1964), en Ciencia y técnica como ideología, $4^{\text {a }}$ edición, Tecnos, Madrid.

Lolas, F. (2002), Temas de Bioética, Editorial Universitaria, Santiago de Chile.

Luna, F. y Salles, A. (2008), Bioética: nuevas reflexiones sobre debates clásicos, Fondo de la Cultura Económica de Argentina, Buenos Aires.

Molina, R., Molina , T. y González, E.(2007), “Madres niñas-adolescentes de 14 años y menos: Un grave problema de salud pública no resuelto en Chile”. Rev. méd. Chile, ene. 2007, vol.135, no.1, p. 79-86, Santiago de Chile.

Romeo, C. (1994), El derecho y la bioética ante los límites de la vida humana, Editorial Centro de Estudios Ramón Areces, Madrid.

Soto, R. (2001), “Derecho Civil de la Persona del Genoma al Nacimiento: Figueroa Yáñez, Gonzalo, Editorial Jurídica de Chile, Santiago, 2001, 308 Páginas”, Ius et Praxis, vol.7, no.2, p.521-531, Talca.

Idem (2002), “El Derecho y la interpretación de los hechos: dos ejemplos de actualidad (Células madre y Clonación)”, Revista de Derecho, V. 13, pág. 75-87, Valdivia. 
Ugarte, J. (2006), El derecho de la vida. El derecho a la vida. Bioética y Derecho. Editorial Jurídica de Chile, Santiago de Chile.

Recibido: 27.07.2013

Aceptado: 02.09.2013 